\title{
Prevalence and Factors Associated with Depression and Anxiety Among First-Year University Students in Bangladesh: A Cross-Sectional Study
}

\author{
Saiful Islam ${ }^{1,2} \cdot$ Rejina Akter $^{1} \cdot$ Tajuddin Sikder $^{1} \cdot$ Mark D. Griffiths $^{3}$
}

Published online: 2 March 2020

(C) The Author(s) 2020

\begin{abstract}
University students, especially those in their first year, not only face challenges related to their personal life but also to their academic performance. Such unfavorable conditions predispose them to psychological illnesses such as depression and anxiety. The present study surveyed first-year undergraduate students to assess the prevalence of depression and anxiety and their potential underlying reasons. A cross-sectional questionnaire was conducted with 400 first-year university students aged between 18 and 23 years residing at Jahangirnagar University (in Bangladesh). After providing informed consent, the participants completed a survey examining socio-demographic variables and behavioral variables, along with the PHQ-9 scale, and the GAD-7 scale. Binary logistic regression was performed to determine the significant associations between the variables under examination. The prevalence rates of moderate to extremely severe levels of depression and anxiety were $69.5 \%$ and $61 \%$, respectively, with no significant gender differences. The main risk factors for depression were unsatisfactory sleep quality and lack of physical exercise. The main risk factor for anxiety was excessive internet use. The prevalence of depression and anxiety levels among first-year university students was high in the present study and appears to confirm the notion that first-year university students are a vulnerable group for mental illnesses. The findings suggest the need for intervention programs, alongside adequate and appropriate supportive services for Bangladeshi university students.
\end{abstract}

Keywords Mental illness · First-year university students $\cdot$ Student mental health · Depression · Anxiety

Mental health illness has become of great public health concern in Bangladesh as elsewhere in the world. Depression, anxiety, stress, and sleeping disorder have become common terms among the people of Bangladesh. Students appear to be very susceptible to such types of

Mark D. Griffiths

mark.griffiths@ntu.ac.uk

Extended author information available on the last page of the article 
mental illnesses, especially first-year university students who move away from their family, move into a new place in a new town or city, and have cope with new environments (Alim et al., 2017). More specifically, when starting at the university, first-year students have a new residence (dormitory), a new daily food pattern, a new study curriculum (including class lectures, laboratory classes, presentations, fieldwork, etc.), new friends, new teachers, and a wide range of new physical environments (Abdallah \& Gabr, 2014; Beiter et al., 2015). The main decision of first-year students is to determine their future career according to their study major. Among students, those who do not adapt quickly to these new daily activities are likely to be susceptible to depression and anxiety.

In the global context, the prevalence of mental illness among first-year university medical students has been reported as being moderate to severe/extremely severe (63.6\% for depression and $78.4 \%$ for anxiety) (Abdallah \& Gabr, 2014). According to the World Health Organization (2018), individuals with severe mental illnesses - moderate to severe depression, bipolar disorder, and schizophrenia and other psychotic disorders - generally have a life expectancy of 10-20 years shorter than the general population (World Health Organization, 2018). Such an assertion suggests the issue is of importance, particularly among university students who are more susceptible to mental illnesses.

There have been various studies that have examined depression and anxiety among the student populations. For instance, the prevalence rates for student depression have been reported to be $43.7 \%$ in India (Kumari et al., 2019), 40.9\% in Pakistan (Rizvi et al., 2015), $37 \%$ in Malaysia (Shamsuddin et al., 2013), 68.5\% in Hong Kong (Lun et al., 2018), $43 \%$ in Saudi Arabia (Kulsoom \& Afsar, 2015), 27.1\% in Turkey (Bayram \& Bilgel, 2008), 63.3\% in Egypt (Abdallah \& Gabr, 2014), 21.8\% in Australia (Lovell et al., 2015) and 23\% in the USA (Beiter et al., 2015). The prevalence rates for student anxiety have been reported to be $54.4 \%$ in Hong Kong (Lun et al., 2018), 47.1\% in Turkey (Bayram \& Bilgel, 2008), 28.5\% in Australia (Lovell et al., 2015), 25\% in the USA (Beiter et al., 2015), 68.6\% in India (Kumari et al., 2019), $74.2 \%$ in Pakistan (Rizvi et al., 2015), 63\% in Malaysia (Shamsuddin et al., 2013), 63\% in Saudi Arabia (Kulsoom \& Afsar, 2015), and 78.4\% in Egypt (Abdallah \& Gabr, 2014).

Despite these studies on depression and anxiety among students, there is a knowledge gap relating to mental illness regarding depression and anxiety among first-year university students in Bangladesh. A previous study of Bangladeshi medical students reported that the prevalence of depression was $54.3 \%$ and the prevalence of anxiety was $64.8 \%$ of students (Alim et al., 2017). A more recent study of Bangladesh university students (across all years as opposed to first-year students only) reported that the prevalence of depression was $52.2 \%$ and the prevalence of anxiety 58.1\% (Mamun et al., 2019).

Recent studies have opined several contributing factors to mental illness including socialdemographic, behavioral, and educational factors. These include gender, residence, relationship status, socioeconomic status, loneliness, personal autonomy, family and peer pressure, academic performance, studying in the English language, heavy lecture schedule, pressure to succeed, and future planning (Abdallah \& Gabr, 2014; Alim et al., 2017; Beiter et al., 2015). In Bangladesh, first-year (fresher) university students often have to live in dormitories, known as to the students as a "gono room" (an overcrowded room where up to 100 students live and sleep together in one large room for at least 6 months). Furthermore, such students can be the victim of ragging (where fresher students can be mentally and physically persecuted, particularly by second-year students) (Mamun et al., 2019).

At present, there is a knowledge gap because, to date, there has been no previous study examining the prevalence of depression and anxiety among first-year university students in 
Bangladesh. Typically, students who live on campus (in dormitories) face ragging and other problems, which make them more susceptible to mental illness. Consequently, the present study investigated mental health issues (i.e., the prevalence of depression and anxiety) among first-year university students who lived in university accommodation in Bangladesh.

\section{Methods}

\section{Participants and Procedure}

A cross-sectional survey was conducted among first-year students of Jahangirnagar University, Dhaka, Bangladesh (all of who lived in university dormitory accommodation). Data were collected from August to October 2019. The dormitories were selected using random sampling. A total of 500 questionnaires were provided in the dormitories. Of the surveys distributed, 440 participants began completing the surveys in their respective dormitories (88\% response rate). After eliminating the incomplete surveys, 400 remained for analysis. The inclusion criteria to participate in the study were being a first-year student and living on campus (in dormitories).

\section{Measures}

\section{Socio-Demographic Measures}

A self-administered survey containing informed consent, questions concerning socio-demographics, and personal lifestyle-related information, as well as psychometric scales to assess depression and anxiety, was used to collect the data. Socio-demographic data were collected including gender, age, religion, number of siblings, father's occupation, monthly family income, permanent residence (and whether it was a rural or urban area), and faculty of study. Monthly family income was categorized into three classes based on monthly family income: low-class (less than 10,000 BDT), middle class (10000-20,000 BDT), and upper class (more than 20,000 BDT). Jahangirnagar University comprises six faculties (i.e., Arts and Humanities, Biological Science, Business Studies, Mathematical \& Physical Sciences, Social Science, and Law).

\section{Personal Lifestyle-Related Data}

The personal lifestyle-related data were collected by asking questions concerning the amount of weekly physical exercise, number of sleeping hours per night, and sleep satisfaction (yes/ no). Sleeping hours were categorized into three classes on the basis of average daily sleeping hours and classed as normal $(7-8 \mathrm{~h})$, less than average $(<6 \mathrm{~h})$ or more than average $(>9 \mathrm{~h})$ (based on Hirshkowitz et al., 2015).

\section{Patient Depression Questionnaire (PHQ-9)}

The PHQ-9 scale is a convenient tool that assesses not only major depression but also the onset of depressive disorder in general population epidemiological studies (Martin et al., 2006). The 9-item scale of the Bangla Patient Health Questionnaire (Chowdhury et al., 2004) was used to 
assess the level of depression. This scale consists of 9 items answered on a four-point Likert scale ranging from 0 ("Not at all") to 3 ("Nearly every day"). The level of depression was categorized into four groups as minimal, mild, moderate, moderately severe, and severe based on scoring $0-4,5-9,10-14,15-19$, and 20-27, respectively. In the present study, those scoring moderate to extremely severe $(\geq 10)$ were classed as having depressive symptoms (Kroenke \& Spitzer, 2002). In the present study, the Cronbach's alpha was 0.79 .

\section{Generalized Anxiety Disorder Assessment (GAD-7)}

The GAD-7 scale is a valid and reliable tool for screening of anxiety and assessing its severity in epidemiological surveys. The 7 item scale of the Bangla Generalized Anxiety Disorder assessment questionnaire (Haque et al., 2018) was used to assess the level of anxiety. This scale consists of 7 items answered on a four-point Likert scale ranging from 0 ("Not at all") to 3 ("Nearly every day"). The level of anxiety was categorized into four groups as minimal, mild, moderate, and severe based on scoring 0-4, 5-9, 10-14, and 15-21 respectively. In this study, those scoring $(\geq 10)$ moderate to extremely severe were placed to determine the existence of anxiety (Spitzer et al., 2006). In the present study, the Cronbach's alpha was 0.76.

\section{Statistical Analysis}

The data were analyzed using Microsoft Excel 2010 and IBM SPSS Statistics version 25. Microsoft Excel was used for data entry, editing, and sorting. Descriptive statistics and some first-order analysis (frequencies, percentages, means, chi-square tests, etc.) were executed using SPSS software. Binary logistic regression was performed with a $95 \%$ confidence interval to determine the significant associations between categorical dependent and independent variables.

\section{Ethics}

The study was carried out in accordance with the Institutional Research Ethics and The Code of Ethics of the World Medical Association (Declaration of Helsinki) for experiments involving humans. Formal ethical approval was granted from the respective authorities including the research team's university ethics committee. The survey data were collected anonymously, and all participants gave their written informed consent to participate. All the participants were provided with information concerning the purpose of the study prior to data collection. The confidentiality of their data, the nature and procedure of the study, the option to take part in the study, and the right to revoke their data at any time from the study were all outlined in the consent form.

\section{Results}

The participants of the study comprised $52.3 \%$ males and $47.8 \%$ females, and their mean age was 19.66 years $(\mathrm{SD}=0.88)$ ranging from 18 to 23 years. The descriptive statistics for all variables are presented in Table 1. The majority of respondents were from lower-class families $(40.3 \%)$, came from a rural area $(59.9 \%)$, did not take regular physical exercise $(55.5 \%)$, were less than normal sleepers (71\%), and were satisfied with their sleep (56.5\%). 


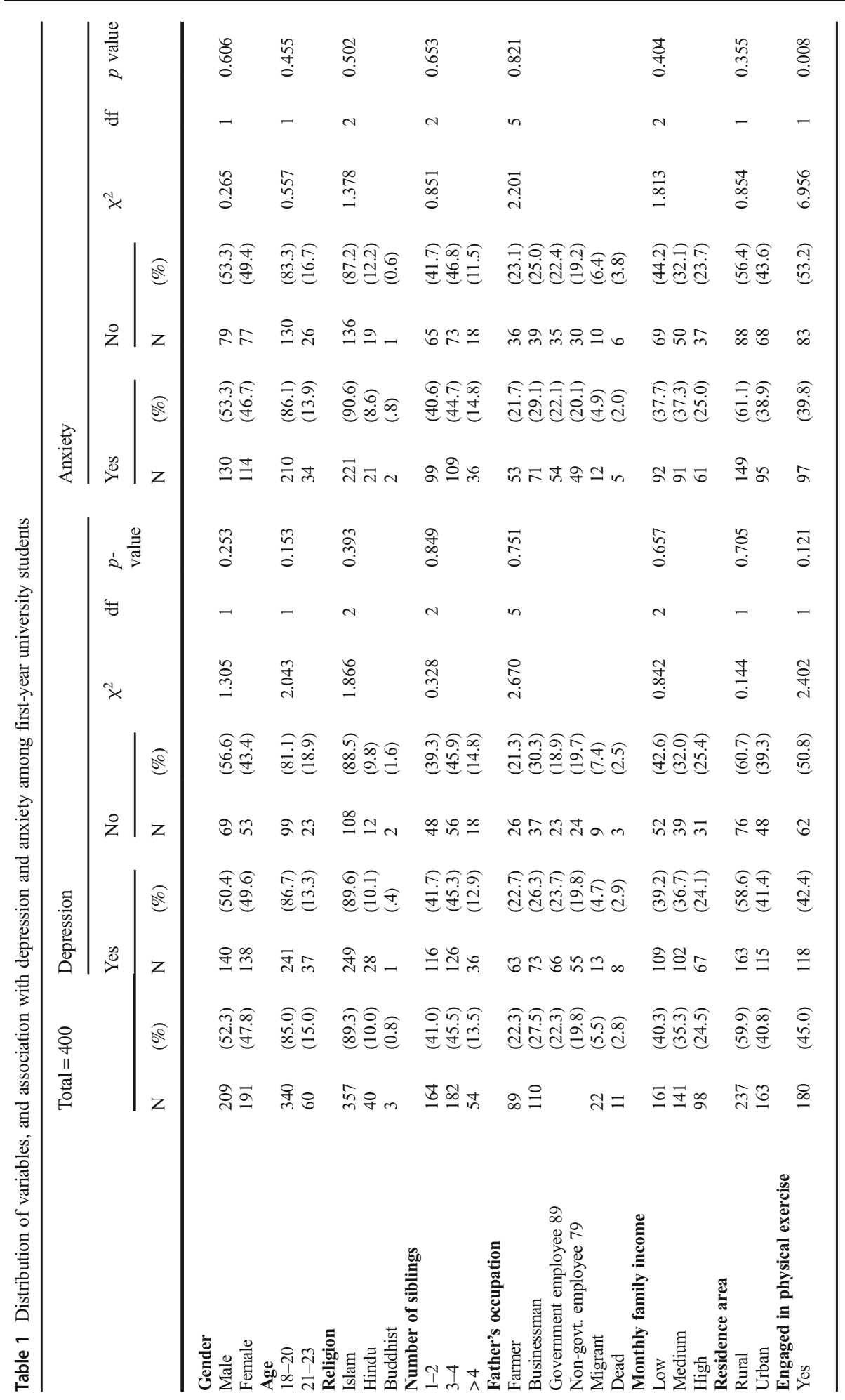




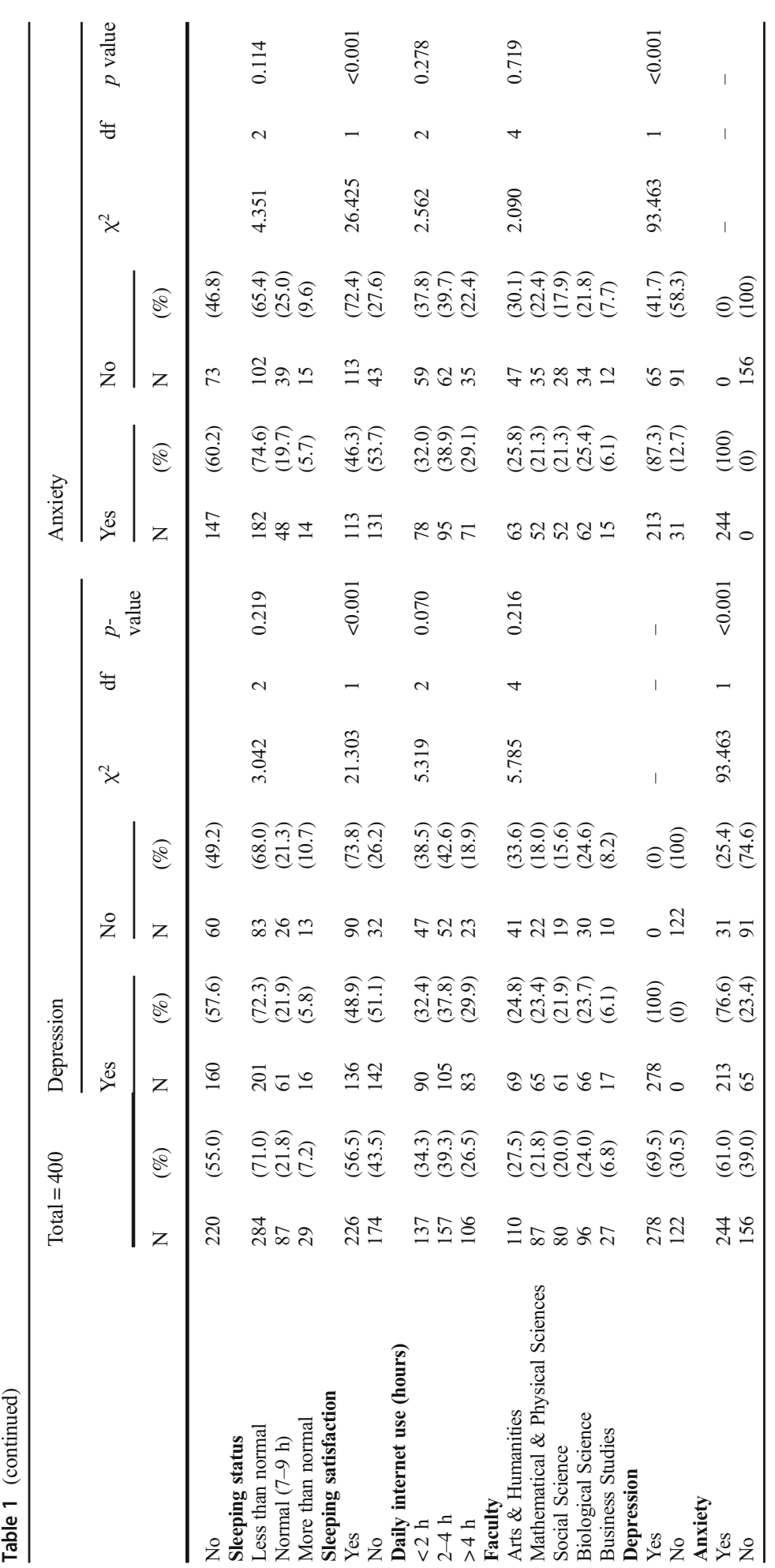


The prevalence rates of moderate to extremely severe levels of depression and anxiety were $69.5 \%$, and $61 \%$, respectively, with no significant gender differences. Based on the PHQ-9 scale, results showed that depression levels were $9.5 \%$ minimal depression, $11.0 \%$ for mild depression, $50.2 \%$ for moderate depression, $15.3 \%$ for moderately severe depression, and $4.0 \%$ severe depression. Based on the GAD-7 scale, results showed that anxiety levels were $18.0 \%$ for minimal anxiety, $21.0 \%$ for mild anxiety, $47.3 \%$ for moderate anxiety, and $13.8 \%$ for severe anxiety. Depressed respondents were significantly more likely than non-depressed respondents to (i) have unsatisfactory sleep quality $\left(\chi^{2}=21.30, d f=1, p<.001\right)$ and (ii) have anxiety $\left(\chi^{2}=93.46, d f=1, p<.001\right)$. Anxious respondents were significantly more likely than non-anxious respondents to (i) not engage in exercise $\left(\chi^{2}=6.96, d f=1, p<.008\right)$, and (ii) have unsatisfactory sleep quality $\left(\chi^{2}=26.43, d f=1, p<.001\right)$.

A binary regression analysis was performed to assess the significant association between dependent and independent variables displayed in Table 2. The respondents having unsatisfactory sleep quality were 2.94 times more likely than the respondents having satisfactory sleep quality to be depressed $(\mathrm{OR}=2.94 ; 95 \% \mathrm{CI}=1.84-4.68, p<.001)$. The respondents not engaging in physical exercise were 1.72 times more likely than the respondents taking physical exercise to have anxiety $(\mathrm{OR}=1.72 ; 95 \%, \mathrm{CI}=1.15-2.59, p=.009)$. The respondents using the internet less than $2 \mathrm{~h}$ daily were 0.53 times less likely than the respondents using the internet more than $4 \mathrm{~h}$ daily to be depressed $(\mathrm{OR}=0.53 ; 95 \% \mathrm{CI}=0.29-0.95, p=.033)$. The respondents using the internet $2-4 \mathrm{~h}$ daily were 0.56 times less likely than the respondents using the internet more than $4 \mathrm{~h}$ daily to be depressed $(\mathrm{OR}=0.56 ; 95 \% \mathrm{CI}=0.32-0.99$, $p=0.045)$. Depressed participants were 9.62 times more likely than non-depressed participants to have anxiety $(\mathrm{OR}=9.62 ; 95 \% \mathrm{CI}=5.87-15.75, p<.001)$.

\section{Discussion}

Mental health illness among undergraduate students at a university is a neglected public health problem in Bangladesh but has become a major issue for mental health policymaking and university campus health services elsewhere in the world (Bayram \& Bilgel, 2008; StewartBrown et al., 2000; Viñas Poch et al., 2004). In this study, the prevalence of depression and anxiety among students was relatively higher than the aforementioned previous studies surveying university students (Adewuya et al., 2006; Nerdrum et al., 2006; Ovuga et al., 2006; Tomoda et al., 2000; Wong, et al., 2006). Although there are few studies concerning mental illness among university students, there is no previous study examining mental illness among first-year university students in Bangladesh. Consequently, there is a knowledge gap that the present study aimed to address by assessing the prevalence of depression and anxiety among first-year students residing at a university in Bangladesh.

The present study indicated that more than half of the students experienced moderate to extremely moderate depression (69.5\%), and/or anxiety (61\%). Compared to the previous study in Bangladesh among medical college students, the prevalence of depression in the present study was higher (69.5\% vs. $54.3 \%)$, and the prevalence of anxiety was lower (61\% vs. 64.8\%) (Alim et al., 2017). Compared to previous study in Bangladesh among all university students (not just first years), the prevalence of both depression (69\% vs. 52.2\%) and anxiety (61\% vs. $58.1 \%$ ) were higher in the present study (Mamun et al., 2019).

In the global context, compared to the previous studies, the prevalence of (i) depression in the present study was higher than in the studies among students in Australia, Egypt, India, 


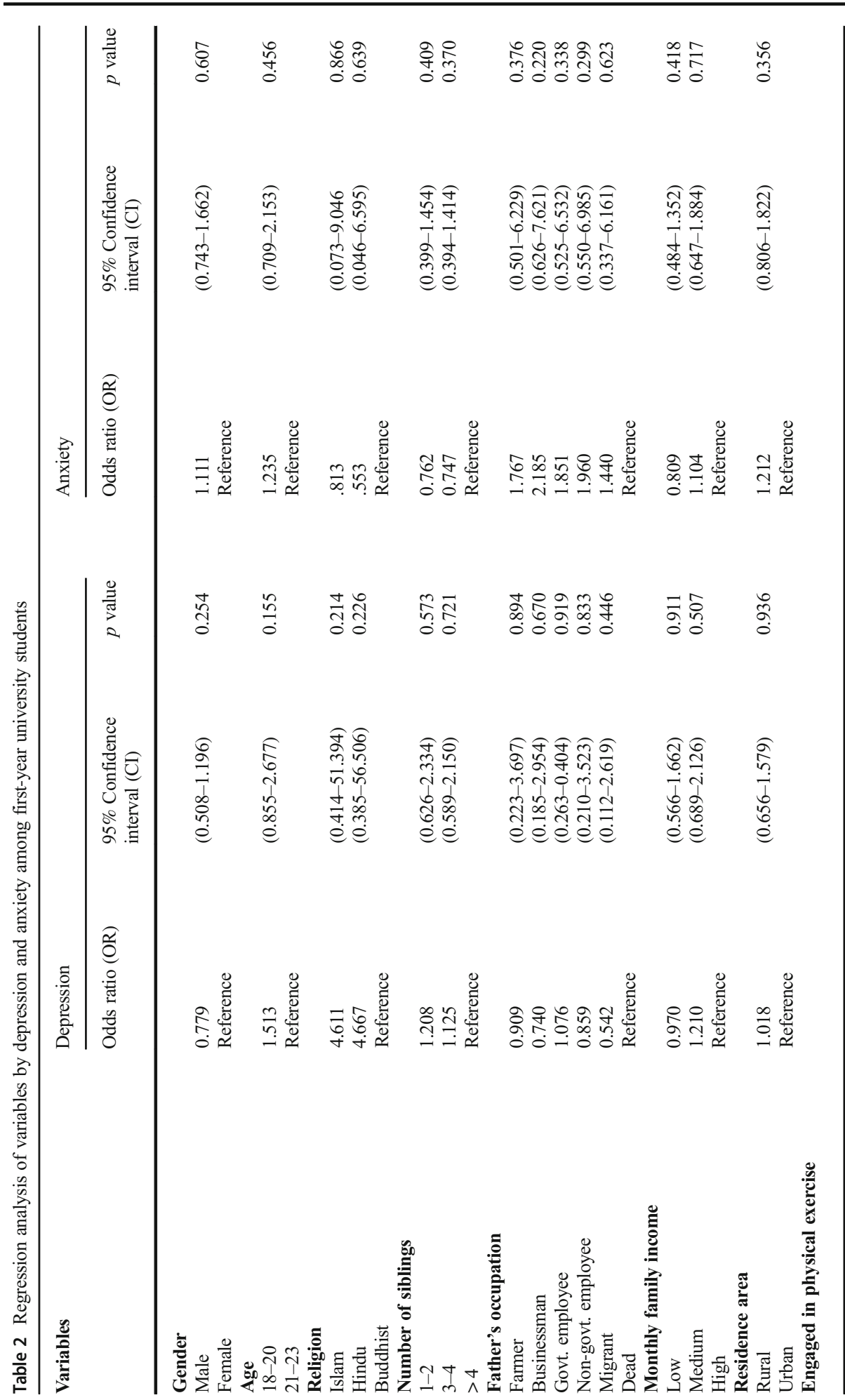


Malaysia, Pakistan, Saudi Arabia, Turkey, and the USA, and (ii) anxiety in the present study was higher than in Australia, Hong Kong, Turkey, and the USA but lower than in Egypt, India, Malaysia, Pakistan, and Saudi Arabia (Abdallah \& Gabr, 2014; Bayram \& Bilgel, 2008; Beiter et al., 2015; Kulsoom \& Afsar, 2015; Kumari et al., 2019; Lun et al., 2018; Lovell et al., 2015; Rizvi et al., 2015; Shamsuddin et al., 2013).

The present study found no significant gender differences for depression or anxiety. Compared to previous studies, there were also no significant gender differences for depression, or anxiety in Bangladesh (Alim et al., 2017), India (Kumari et al., 2019), Malaysia (Shamsuddin et al., 2013), Saudi Arabia (Kulsoom \& Afsar, 2015), Turkey (Bayram \& Bilgel, 2008), Australia (Lovell et al., 2015), and the USA (Beiter et al., 2015). However, one Egyptian study reported that male university students were more prone to depression than female students but that female students were more likely to suffer anxiety than male students (Abdallah \& Gabr, 2014).

In the present study, no statistically significant association was found between any of the socio-demographic variables (including age, religion, number of siblings, father's occupation, monthly family income, residence area, and faculty of study) and depression or anxiety (see Table 1). In the study of Bangladesh medical students, there was also no significant relationship between socio-demographic variables and depression or anxiety (Alim et al., 2017). A previous study in Malaysia also reported no significant relationship between some socio-demographic variables (including gender, ethnicity, study major, monthly family income) and depression or anxiety (Shamsuddin et al., 2013). However, the same study reported significant differences with regard to age (students older than 20 years more likely to be depressed and anxious than those aged 19 years or younger) and permanent residence (those coming from rural areas more likely to be depressed and anxious than those coming from urban areas), and depression or anxiety (Shamsuddin et al., 2013). In Egypt, a previous study reported a significant association between depression and socio-demographic variables including gender (males more likely to be depressed than females), residence area (those coming from rural areas more likely to be depressed than those coming from a rural area), and socio-economic status (those coming from middle class families more likely to be depressed than lower and higher class families), but no significant differences between anxiety and socio-demographic variables except for gender (females more likely to be anxious than males) (Abdallah \& Gabr, 2014).

The present study only obtained significant associations concerning (i) lack of sleep satisfaction and depression, (ii) lack of physical exercise and anxiety, (iii) excessive daily internet use and depression, and (iv) depression and anxiety (Table 2). This compares with a recent Bangladeshi study (i.e., Mamun et al., 2019) that reported significant associations concerning socio-economic status (those coming from a lower class family more likely to be depressed than those coming from middle and higher class families), physical exercise (those engaging in less physical exercise more likely to be depressed than those engaging regular physical exercise), smoking (cigarette smokers more likely to be depressed than those being non-smokers), and relationship status (those in a relationship more likely to be anxious than those who were single). Previous studies have also reported that mental health illness was correlated with detrimental behaviors such as lack of physical exercise, poor sleep habit, poor diet, smoking, and noncompliance with medical care guidance (refusal of medicines or treatments) (Beiter et al., 2015; Doom \& Haeffel, 2013).

Finally, it should be reiterated that the prevalence rates of depression $(69.5 \%)$ and anxiety (61\%) among first-year university students in Bangladesh were somewhat higher compared to the aforementioned studies carried out in other countries. The present study found that the most 
significant factors associated with the high prevalence of mental health illnesses (i.e., depression and anxiety) were unsatisfactory sleep quality, lack of physical exercise, and excessive use of the internet. Other factors that were not investigated but which may have contributed to the high prevalence rates include ragging, living and sleeping in large dormitories, loneliness, personal autonomy, family and peer pressure, academic performance, studying in English language, heavy lecture schedule, pressure to succeed, and future planning, as well as factors related to being in new and different environments with new people (e.g., new city, new residence, new curricula, new friends, new teachers, etc.) (Abdallah \& Gabr, 2014; Alim et al., 2017; Beiter et al., 2015).

\section{Implications}

Based on the relatively high prevalence rates of depression and anxiety found among first-year university students, it appears that special measures are needed to help protect this vulnerable population. University authorities and healthcare professionals need their attention drawn to this vulnerable population so that such illnesses can be prevented in the first place. The university authorities need to raise student awareness about the intake of regular exercise, the moderate use of internet, and the improving sleep quality. Mental health programs should be organized on campus to raise awareness of mental health among university students. University students should be provided with the information and skills to deal with factors mentioned in other studies such as loneliness, autonomous personal life, family and peer pressure, academic performance, studying in the English language, heavy lecture schedule, pressure to succeed, and future planning (Abdallah \& Gabr, 2014; Alim et al., 2017). However, based on the findings of the present study, intervention and awareness programs need to emphasize the importance of regular exercise, sleep hygiene, and moderate use of internet in helping prevent depression and anxiety.

\section{Limitations}

The present study is not without its limitations which should be taken into account when interpreting the data. Firstly, the study was cross-sectional in nature so no causal mechanisms can be identified related to the variables under investigation, A longitudinal study would help overcome this limitation but are also time-consuming and expensive and are therefore very difficult to undertake in a Bangladeshi context. Secondly, the study utilized a self-report methodology that might have prejudiced the outcomes through well-known biases such as social desirability and memory recall. Thirdly, this study was conducted at only one university in Bangladesh and among first-year students residing on campus with only a modest sample size. Therefore, the findings cannot necessarily be generalized to other student populations in Bangladesh or students in other countries. Finally, pre-diagnosed psychiatric illnesses that excluded individuals from taking part in the study were taken on the basis of student self-report and not corroborated with any third party. Therefore, it is possible that some students may have completed the survey even though they had confirmed mental health condition.

\section{Conclusion}

The present study gathers novel information that addresses a confirmed knowledge gap regarding mental illness (i.e., depression and anxiety) among first-year university students in 
Bangladesh. This study found a high prevalence of depression and anxiety compared to the existing global studies and highlighted a number of risk factors that are significantly associated with depression and/or anxiety (i.e., lack of physical exercise, excessive internet use, lack of sleep satisfaction - factors that are associated in and of themselves). These risk factors should be addressed by the respective Bangladeshi authorities (e.g., university counselors and practitioners, public health policymakers) in trying to facilitate a student-friendly environment that protects against (and helps prevent) mental health problems among first-year students.

Acknowledgments Firstly, the authors would like to express the most profound appreciation to all of the respondents who participated in this study enthusiastically and voluntarily. Secondly, the authors highly appreciate the cooperation of the respective authorities. Furthermore, the authors are very grateful to Md. Rakib Hossen, Md. Nayeem Islam, Tanvir Ahmed Shuvo, Ebrahim Howlader, Nazzashi Sultan Nasib, Saifur Rahman Sarker, Fatema Akter Shanta, (Department of Public Health \& Informatics), and Dilshad Afroze Chowdhury (Bangabandhu Institute of Comparative Literature \& Culture) for their support during data collection periods.

Funding Information Self-funded.

\section{Compliance with Ethical Standards}

Conflict of Interest The authors declare that they have no competing interests.

Ethical Approval The study was carried out in accordance with the Institutional Research Ethics and the Code of Ethics of the World Medical Association (Declaration of Helsinki) for experiments involving human participants. Informed written consent was obtained prior to the selection of the students and before data was gathered.

Open Access This article is licensed under a Creative Commons Attribution 4.0 International License, which permits use, sharing, adaptation, distribution and reproduction in any medium or format, as long as you give appropriate credit to the original author(s) and the source, provide a link to the Creative Commons licence, and indicate if changes were made. The images or other third party material in this article are included in the article's Creative Commons licence, unless indicated otherwise in a credit line to the material. If material is not included in the article's Creative Commons licence and your intended use is not permitted by statutory regulation or exceeds the permitted use, you will need to obtain permission directly from the copyright holder. To view a copy of this licence, visit http://creativecommons.org/licenses/by/4.0/.

\section{References}

Abdallah, A. R., \& Gabr, H. M. (2014). Depression, anxiety and stress among first year medical students in an Egyptian public university. International Research Journal of Medicine and Medical Sciences, 2(1), 11-19.

Adewuya, A. O., Ola, B. A., Aloba, O. O., Mapayi, B. M., \& Oginni, O. O. (2006). Depression amongst Nigerian university students: Prevalence and socio-demographic correlates. Social Psychiatry and Psychiatric Epidemiology, 41(8), 676-678.

Alim, S. A. H., Rabbani, M. G., Karim, E., Mullick, M. S., Mamun, A., et al. (2017). Assessment of depression, anxiety and stress among first year MBBS students of a public medical college, Bangladesh. Bangladesh Journal of Psychiatry, 29(1), 23-29.

Bayram, N., \& Bilgel, N. (2008). The prevalence and socio-demographic correlations of depression , anxiety and stress among a group of university students. Social Psychiatry and Psychiatric Epidemiology, 43(8), 667672 .

Beiter, R., Nash, R., Mccrady, M., Rhoades, D., Linscomb, M., Clarahan, M., \& Sammut, S. (2015). The prevalence and correlates of depression, anxiety, and stress in a sample of college students. Journal of Affective Disorders, 173, 90-96. 
Chowdhury, A., Ghosh, S., \& Sanyal, D. (2004). Bengali adaptation of brief patient health questionnaire for screening depression at primary care. Journal of the Indian Medical Association, 102(10), 544-547.

Doom, J. R., \& Haeffel, G. J. (2013). Teasing apart the effects of cognition, stress, and depression on health title. American Journal of Health Behavior, 37(5), 610-619.

Haque, M., Das, C., Ara, R., Alam, M., Ullah, S., \& Hossain, Z. (2018). Prevalence of generalized anxiety disorder and its effect on daily living in the rural community of Rajshahi. Journal of Teachers Association, 27(1), 14-23.

Hirshkowitz, M., Whiton, K., Albert, S. M., Alessi, C., Bruni, O., DonCarlos, L., Hazen, N., Herman, J., Adams Hillard, P. J., Katz, E. S., Kheirandish-Gozal, L., Neubauer, D. N., O'Donnell, A. E., Ohayon, M., Peever, J., Rawding, R., Sachdeva, R. C., Setters, B., Vitiello, M. V., \& Ware, J. C. (2015). National Sleep Foundation's updated sleep duration recommendations: final report. Sleep Health, 1(4), 233-243.

Kroenke, K., \& Spitzer, R. (2002). The PHQ-9: a new depression diagnostic and severity measure. Psychiatric Annals, 32(9), 509-521.

Kulsoom, B., \& Afsar, N. A. (2015). Stress, anxiety, and depression among medical students in a multiethnic setting. Neuropsychiatric Disease and Treatment, 11, 1713-1722.

Kumari, R., Langer, B., Jandial, S., Gupta, R., Raina, S. K., \& Singh, P. (2019). Psycho-social health problems: prevalence and associated factors among students of professional colleges in Jammu. Indian Journal of Community Health, 31(01), 43-49.

Lovell, G. P., Nash, K., Sharman, R., \& Lane, B. R. (2015). A cross-sectional investigation of depressive, anxiety, and stress symptoms and health-behavior participation in Australian university students. Nursing and Health Sciences, 17, 134-142.

Lun, K. W., Chan, C. K., Ip, P. K., Ma, S. Y., Tsai, W. W., Wong, C. S., Wong, C. H., Wong, T. W., \& Yan, D. (2018). Depression and anxiety among university students in Hong Kong. Hong Kong Medical Journal (Xianggang Yi Xue Za Zhi), 24(5), 466-472.

Mamun, M. A., Hossain, M. S., \& Griffiths, M. D. (2019). Mental health problems and associated predictors among Bangladeshi students. International Journal of Mental Health and Addiction., 1-15. https://doi. org/10.1007/s11469-019-00144-8.

Martin, A., Rief, W., Klaiberg, A., \& Braehler, E. (2006). Validity of the brief patient health questionnaire mood scale (PHQ-9) in the general population. General Hospital Psychiatry, 28(1), 71-77.

Nerdrum, P., Rustøen, T., \& Rønnestad, M. H. (2006). Student psychological distress: a psychometric study of 1750 Norwegian 1st-year undergraduate students. Scandinavian Journal of Educational Research, 50(1), 95-109.

Ovuga, E., Boardman, J., \& Wasserman, D. (2006). Undergraduate student mental health at Makerere University, Uganda. World Psychiatry : Official Journal of the World Psychiatric Association (WPA), 5(1), 51-52.

Rizvi, F., Qureshi, A., Rajput, A. M., \& Afzal, M. (2015). Prevalence of depression, anxiety and stress (by DASS scoring system) among medical students in Islamabad, Pakistan. British Journal of Medicine \& Medical Research, 8(01), 69-75.

Shamsuddin, K., Fadzil, F., Ismail, W. S. W., Shah, S. A., Omar, K., Muhammad, N. A., et al. (2013). Correlates of depression, anxiety and stress among Malaysian university students. Asian Journal of Psychiatry, 6(4), 318-323.

Spitzer, R. L., Kroenke, K., Williams, J. B. W., \& Lo, B. (2006). A brief measure for assessing generalized anxiety disorder. Archives of Internal Medicine, 166, 1092-1097.

Stewart-Brown, S., Evans, J., Patterson, J., Petersen, S., Doll, H., Balding, J., \& Regis, D. (2000). The health of students in institutes of higher education: an important and neglected public health problem? Journal of Public Health Medicine, 22(4), 492-499.

Tomoda, A., Mori, K., Kimura, M., Takahashi, T., \& Kitamura, T. (2000). One-year prevalence and incidence of depression among first-year university students in Japan: a preliminary study. Psychiatry and Clinical Neurosciences, 54(5), 583-588.

Viñas Poch, F., Villar, E., Caparros, B., Juan, J., Cornella, M., \& Perez, I. (2004). Feelings of hopelessness in a Spanish university population. Social Psychiatry and Psychiatric Epidemiology, 39(4), 326334.

Wong, J. G. W. S., Cheung, E. P. T., Chan, K. K. C., Ma, K. K. M., \& Tang, S. W. (2006). Web-based survey of depression, anxiety and stress in first-year tertiary education students in Hong Kong. Australian and New Zealand Journal of Psychiatry, 40(9), 777-782.

World Health Organization (2018). WHO guidelines: Management of physical health conditions in adults with severe mental disorders. Retrieved February 15, 2020, from: https://www.who.int/mental health/evidence/guidelines_severe_mental_disorders_web_note_2018/en/ 
Publisher's Note Springer Nature remains neutral with regard to jurisdictional claims in published maps and institutional affiliations.

\section{Affiliations}

\section{Saiful Islam ${ }^{1,2} \cdot$ Rejina Akter $^{1} \cdot$ Tajuddin Sikder $^{1} \cdot$ Mark D. Griffiths $^{3}$}

Saiful Islam

saiful.ju@yahoo.com

Rejina Akter

rejinadphi@gmail.com

Tajuddin Sikder

sikder@juniv.edu

1 Department of Public Health and Informatics, Jahangirnagar University, Savar, Dhaka, Bangladesh

2 Institute of Allergy and Clinical Immunology of Bangladesh (IACIB), Savar, Dhaka, Bangladesh

3 International Gaming Research Unit, Psychology Department, Nottingham Trent University, 50 Shakespeare Street, Nottingham NG1 4FQ, UK 